
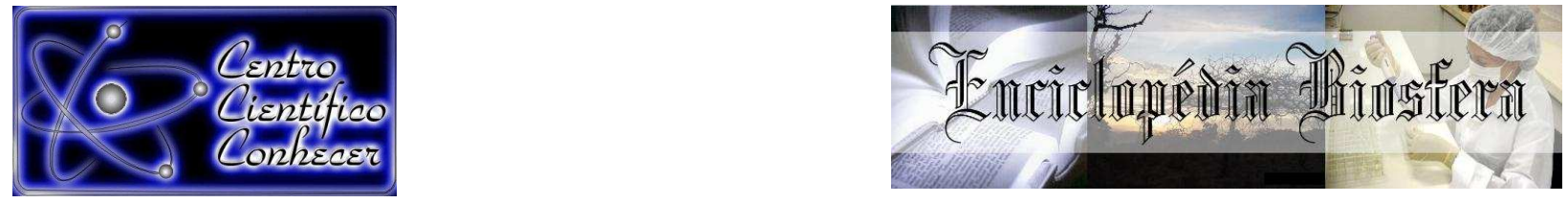

\title{
ATIVIDADE ANTIMICROBIANA DE BACTÉRIAS ENDOFÍTICAS ISOLADAS DE Jacaranda decurrens Cham. (CAROBINHA-DO-CAMPO)
}

Aysha Jussara Ivonilde Carrim ${ }^{1}$, Igor Daniel Alves Ribeiro², Marcus Vinícius Forzani Araújo $^{3}$, Bruno Francesco Rodrigues de Oliveira ${ }^{4}$, José Daniel Gonçalves Vieira ${ }^{5}$

1 Doutoranda em Ciências Ambientais, Universidade Federal de Goiás

2 Graduando do curso de Biotecnologia, Universidade Federal de Goiás

3 Mestrando em Ciências Ambientais, Universidade Federal de Goiás

4 Professor Mestre do Departamento de Bioquímica e Biologia Molecular do Instituto de Ciências Biológicas da Universidade Federal de Goiás

(bfro.francesco@gmail.com)

5 Professor Doutor do Departamento de Microbiologia, Imunologia, Parasitologia e Patologia do Instituto de Patologia Tropical e Saúde Pública da Universidade Federal de Goiás Goiânia-Brasil

Recebido em: 08/04/2016 - Aprovado em: 30/05/2016 - Publicado em: 20/06/2016 DOI: 10.18677/Enciclopedia_Biosfera_2016_122

RESUMO
Bacteriocinas são antibióticos classificados como produtos naturais, ou seja, metabólitos secundários produzidos por bactérias. Endofíticos, micro-organismos que possuem a planta como hospedeira em pelo menos uma etapa de vida, são bons exemplos de produtores de bacteriocinas. O objetivo do presente trabalho foi avaliar a atividade antimicrobiana pela provável produção de bacteriocinas por bactérias endofíticas isoladas de Jacarranda decurrens Cham. frente a diferentes cepas indicadoras e a sensibilidade esses metabolitos bioativos à temperatura (75$80^{\circ} \mathrm{C}$ ) e a tripsina em dois meios de cultura diferentes. Foram utilizadas 10 isolados bacterianos endofíticos previamente isolados a partir de Jacaranda decurrens Cham. Destes isolados, $70 \%$ apresentaram atividade antimicrobiana, evidenciada pela formação de halos de inibição em placas de ágar com dupla camada frente a no mínimo uma ou mais das 15 cepas bacterianas indicadoras utilizadas. Os compostos antimicrobianos gerados pelos isolados CAR 4, CAR 5 e CAR 7 foram termolábeis e resistentes à tripsina. Os metabólitos produzidos pelo isolado CAR 6 foram sensíveis ao calor e à enzima e os isolados CAR 2, CAR 4, CAR 5 e CAR 7 também produziram substâncias sensíveis para essas condições. A produção dos compostos só ocorreu no meio de cultura 523 e não foi observada a presença de bacteriófagos. Substâncias com atividade bacterioginogênica e com largo espectro de ação contra organismos patogênicos foram geradas pelas bactérias endofíticas da planta medicinal, assim apresentando interessante potencial para serem aplicados como antimicrobianos e em controle biológico.

PALAVRAS-CHAVE:bactérias, endofíticos, potencial bacteriocinogênico. 


\title{
ANTIMICROBIAL ACTIVITY OF ENDOPHYTIC BACTERIA ISOLATED FROM Jacaranda decurrens Cham. (CAROBINHA-DO-CAMPO)
}

\begin{abstract}
Bacteriocins are antibiotics classified as natural products, in other words, secondary metabolites produced by bacteria. Endophytic, micro-organisms that have plants as hosts in at least one life stage, are a good example of bacteriocin producers. The aim of this work was to evaluate the antimicrobial activity probably due to bacteriocin production by endophytic bacteria isolated from Jacarranda decurrens Cham. against different indicator strains and the bioactive metabolites sensibility to temperature (75$80^{\circ} \mathrm{C}$ ) and to trypsin in two different media. It was used 10 endophytic bacterial isolates previously isolated from Jacaranda decurrens Cham. $70 \%$ of the isolated presented antimicrobial activity, evidenced by inhibition halos in agar plates against at least one of the 15 indicators strains. The antimicrobial compounds generated by the isolates CAR 4, CAR 5 and CAR 7 were thermolabile and resistant to trypsin. The metabolites produced by CAR 6 were sensible to the heat and the enzymatic treatment and the isolates CAR 2, CAR 4, CAR 5 and CAR 7 also produced substances sensible to these conditions. The production of the antimicrobial compounds just happened in media 523 and it was not observed the presence of bacteriophages. Substances with bacteriocinogenic activity and with broad spectrum of action against pathogenic organisms was produced by the endophytic bacteria from the medicinal plant, thus exhibiting interesting potential to be applied as antimicrobials and in biological control.
\end{abstract}

KEYWORDS: bacteria, endophytic, bacteriocinogenic potential.

\section{INTRODUÇÃO}

Produtos naturais são metabólitos derivados e/ou subprodutos do metabolismo de plantas, animais e micro-organismos (OLIVEIRA et al., 2013). Estes produtos têm sido explorados para uso humano a milhares de anos, sendo os vegetais os mais estudados na produção destas biomoléculas empregadas na medicina (CRAGG \& NEWMAN, 2013). Cerca de $40 \%$ de todos os medicamentos disponíveis no mercado, foram desenvolvidos a partir de fontes naturais (WHO, 2011). Na sociedade moderna existe uma necessidade urgente na descoberta de novas biomoléculas com potencial antimicrobiano, antitumoral e de aplicação na agricultura (RUTLEDGE \& CHALLIS, 2015).

Endofíticos são micro-organismos que habitam, em pelo menos uma fase do seu ciclo de vida, o interior de vegetais sem causar danos aos mesmos (PANDEY et al., 2012; CHEBOTAR et al., 2015). Estes micro-organismos são comumente associados a produção de muitas biomoléculas de interesse biotecnológico, tais como antibióticos e outros fármacos, enzimas, moléculas promotoras de crescimento vegetal, controle de patógenos, além de exercerem outras funções de importância para a sobrevivência do hospedeiro (CHEBOTAR et al., 2015).

Bacteriocinas são compostos de natureza geralmente proteica produzidos por bactérias, que em baixas concentrações possuem ação bactericida ou bacteriostática frente a espécies bacterianas sensíveis (MARTINEZ et al., 2013). São por definição "antibióticos", diferenciando-se dos mesmos pela natureza protéica e especificidade (COTTER et al., 2013; MESSAOUDI et al., 2013). Estas biomoléculas participam do sistema de defesa de algumas bactérias, que incluem outros metabólitos como antibióticos, agentes líticos, diversas exotoxinas protéicas, bacteriófagos ou produtos do metabolismo primário (SHARMILA \& VIDYA, 2015). 
Estas características facilitam a competição por nichos ecológicos no ambiente em que vivem, frente a estirpes taxonomicamente afins (ZHENG et al., 2015; GHOUL et al., 2015).

As bacteriocinas são estudadas desde 1925, quando Gratia constatou a produção de colicina, uma proteína altamente específica e inibitória produzida por Escherichia coli frente a outros isolados de $E$. coli e outras espécies taxonomicamente afins, assim como bacteriocinas produzidas por bactérias ácidoláticas (LAB). As moléculas produzidas por LAB são amplamente estudadas devido ao potencial como bioconservantes aplicáveis aos alimentos desde que apresentem grau de segurança GRAS - generally recognized as safe (UDHAYASHREE et al., 2012; MESSAOUDI et al., 2013). O mecanismo de ação esta relacionado a geração de poros na membrana celular ou inibição da síntese do peptideoglicano, interessantes e bem explorados alvos para novos agentes antibacterianos, tornando esses peptídeos candidatos potenciais para novas drogas (CAVERA et al., 2015).

Este trabalho teve como objetivo detectar a capacidade inibitória de bactérias endofíticas isoladas de Jacaranda decurrens Cham. (carobinha-docampo), planta medicinal de uso popular na região do Cerrado, frente a diferentes bactérias, incluindo importantes micro-organismos patogênicos e deteriorantes, além de determinar a sua estabilidade frente ao calor e a enzimas proteolíticas.

\section{MATERIAL E MÉTODOS}

\section{Micro-organismos endofíticos e condições de crescimento}

Foram utilizados 10 isolados bacterianos endofíticos (Quadro 1) previamente isolados a partir de folhas e caules de Jacaranda decurrens Cham. (CARRIM et al., 2006). Os isolados pertencem a coleção de micro-organismos do Laboratório de Microbiologia Ambiental e Biotecnologia (LAMAB) da Universidade Federal de Goiás (UFG). As bactérias empregadas no ensaio de produção de bacteriocinas foram cultivadas em Caldo Nutriente (CN), e as cepas indicadoras foram crescidas em caldo BHI (Brain Heart Infusion). Os micro-organismos foram incubados sob agitação mecânica a $180 \mathrm{rpm}, 3^{\circ} \mathrm{C}$, por 24-48 horas.

QUADRO 1 - Isolados bacterianos endofíticos de
Jacaranda decurrens

\section{Determinação da atividade antimicrobiana}

A atividade antimicrobiana foi determinada pelo método de sobrecamada, utilizando o meio $523\left(10 \mathrm{~g} \mathrm{~L}^{-1}\right.$ de sacarose, $4 \mathrm{~L}^{-1}$ de extrato de levedura, $8,0 \mathrm{~g} \mathrm{~L}^{-1}$ de caseína hidrolisada, 0,3 $\mathrm{g} \mathrm{L}^{-1}$ de $\mathrm{MgSO}_{4}, 2,0 \mathrm{~g} \mathrm{~L}^{-1}$ de $\mathrm{K}_{2} \mathrm{HPO}_{4}$ e $15 \mathrm{~g} \mathrm{~L}^{-1}$ de ágar) de 
KADO \& HESKETT (1970) e o meio NYA $\left(8,0 \mathrm{~g} \mathrm{~L}^{-1}\right.$ de caldo nutriente, $2,0 \mathrm{~g} \mathrm{~L}^{-1}$ de extrato de levedura, $2 \mathrm{~g} \mathrm{~L}^{-1}$ de $\mathrm{K}_{2} \mathrm{HPO}_{4}, 0,5 \mathrm{~g} \mathrm{~L}^{-1}$ de $\mathrm{KH}_{2} \mathrm{PO}_{4}, 2,5 \mathrm{~g} \mathrm{~L}^{-1}$ de glucose e $15 \mathrm{~g} \mathrm{~L}^{-1}$ de ágar, pH 7,4) descrito por VIDAVER (1967). Alíquotas de $10 \mu \mathrm{L}$ dos isolados bacterianos, previamente crescidos em $\mathrm{CN}$, foram inoculadas em placas com os diferentes meios avaliados. As placas foram mantidas a $30^{\circ} \mathrm{C}$ por 48 horas, após este período, as mesmas foram expostas à luz ultravioleta (UV, microbicida, $\lambda=254 \mathrm{~nm}$ ) por 30 minutos para a inativação do crescimento bacteriano (ROMEIRO, 1989).

Após a exposição à luz ultravioleta as placas foram recobertas com uma sobrecamada de meio $\mathrm{BHI}$ semi-sólido (ágar a 0,6\%; m/v), inoculado com $50 \mu \mathrm{L}$ da suspensão bacteriana indicadora padronizada para metade da turvação do tubo №1 da escala de MacFarland. Esta padronização foi utilizada para inóculo dos microorganismos nos demais experimentos realizados. As placas foram incubadas a $30^{\circ} \mathrm{C}$ e os halos de inibição determinados após 24, 48, 72, 96 e 120 horas de crescimento. Foram utilizadas as bactérias indicadoras: Enterobacter aerogenes ATCC 13048, Bacillus subtilis ATCC 6633, Bacillus subtilis 008, Bacillus cereus ATCC 14578, Rhodococcus equi CCT 0541, Staphylococcus aureus ATCC 29737, Micrococcus luteus ATCC 9341, Corynebacterium glutamicum ATCC 13032, Salmonella typhimurium ATCC 14028, Salmonella choleraisuis ATCC 10708, Pseudomonas aeruginosa ATCC 9027, Serratia marscecens ATCC 147565, Escherichia coli ATCC 25922, Agrobacterium tumefaciens Ach5 e Agrobacterium tumefaciens ATCC 33970/C58.

A atividade antimicrobiana também foi avaliada por ensaio com sobrenadante do crescimento em meio líquido. Para este ensaio $0,5 \mathrm{~mL}$ de uma suspensão bacteriana dos diferentes isolados foram inoculadas em frascos Erlenmeyers de $250 \mathrm{~mL}$ contendo $50 \mathrm{~mL}$ dos dois meios de cultivo. Os frascos foram mantidos sob agitação a $130 \mathrm{rpm}, 30^{\circ} \mathrm{C}$ por 48 horas. Após este período, as culturas bacterianas foram centrifugadas durante cinco minutos a $10.000 \mathrm{rpm}, 4^{\circ} \mathrm{C}$. $\mathrm{O}$ sobrenadante obtido foi armazenado em tubos Eppendorff a $-20^{\circ} \mathrm{C}$. Para o ensaio, as bactérias indicadoras previamente padronizadas foram inoculadas com o auxílio de um swab em placas de Petri contendo ágar Müller-Hinton (MH). Em seguida, poços de $5 \mathrm{~mm}$ de diâmetro foram perfurados e $20 \mu \mathrm{l}$ do sobrenadante das culturas foram transferidos para os mesmos. As placas foram incubadas a $30^{\circ} \mathrm{C}$ por 48 horas, após este tempo a formação de halos de inibição determinada.

\section{Detecção de bacteriófagos}

Para a detecção de bacteriófagos, foi utilizada metodologia adaptada de PUGSLEY \& OUDEGA (1987). Inicialmente as bactérias supostamente produtoras de bacteriocinas (produtoras de halo de inibição) foram crescidas em placas de Petri contendo ágar 523 por quatro dias a $30^{\circ} \mathrm{C}$. Após este período, os meios de cultura foram fragmentados com 0 auxilio de um estilete esterilizado e os fragmentos transferidos individualmente para tubos de ensaio contendo 5,0 mL de caldo MüllerHinton (Difco). Os frascos foram agitados em vórtex por cinco minutos e em seguida centrifugados a $13.500 \mathrm{~g}$ por cinco minutos, a $4^{\circ} \mathrm{C}$. Aproximadamente um volume de $1,0 \mathrm{~mL}$ do sobrenadante foi transferido para tubos Eppendorf e 2-5 gotas de clorofórmio foram adicionadas aos mesmos. Os tubos foram mantidos sob refrigeração a $4^{\circ} \mathrm{C}$.

Para a detecção de bacteriófagos os sobrenadantes foram diluídos até $10^{-4}$. Em seguida, $100 \mu \mathrm{L}$ das diferentes diluições foram adicionados a $5,0 \mathrm{~mL}$ de ágar semi-sólido Müller-Hinton (ágar a $0,5 \% ; \mathrm{m} / \mathrm{v}$ ) contendo $100 \mu \mathrm{L}$ de suspensão das ENCICLOPÉDIA BIOSFERA, Centro Científico Conhecer - Goiânia, v.13 n.23; p.1377 
bactérias indicadoras, previamente padronizadas. Os tubos foram então vertidos em placas de Petri contendo ágar Müller-Hinton solidificado. O material foi incubado a $30^{\circ} \mathrm{C}$ por 48 horas e o desenvolvimento de placas de lise foi indicativo da presença de bacteriófagos.

\section{Avaliação da estabilidade térmica e susceptibilidade a tripsina dos compostos antimicrobianos}

Para avaliar a estabilidade dos compostos de provável natureza bacteriocinogênica frente ao calor, os micro-organismos produtores foram crescidos em meio ágar 523 a $30^{\circ} \mathrm{C}$ por 48 horas. Após este período, as placas de Petri com o crescimento foram expostas à luz ultravioleta (UV, microbicida, $\lambda=254 \mathrm{~nm}$ ) por 30 minutos (ROMEIRO, 1989) para inativação das bactérias. As placas foram então incubadas a $75-80^{\circ} \mathrm{C}$ durante 25 minutos e resfriadas a temperatura ambiente por 30 minutos. Após este tempo as mesmas foram recobertas com 5,0 mL de ágar MüllerHinton contendo $100 \mu \mathrm{L}$ do crescimento da cepa indicadora previamente padronizadas. As placas foram incubadas por 24 horas a $30^{\circ} \mathrm{C}$ e os halos de inibição do crescimento foram comparados com o controle negativo sem tratamento térmico.

Para a determinação da suscetibilidade a tripsina pancreática bovina (Calbiochem, California/USA) $\left(5,0 \mathrm{mg} \mathrm{ml}^{-1}\right)$. Cerca de 5,0 $\mu \mathrm{L}$ da solução enzimática foram inoculados na borda das colônias bacterianas, previamente crescidas em meio sólido. As placas foram incubadas por 4 horas a $30^{\circ} \mathrm{C}$ e recobertas com $5,0 \mathrm{~mL}$ de ágar Müller-Hinton contendo $100 \mu \mathrm{L}$ de suspensão da bactéria indicadora previamente padronizada. As placas foram incubadas por 24 horas a $30^{\circ} \mathrm{C}$, e os halos de inibição do crescimento foram comparados com um controle sem tratamento enzimático (IACOBELLIS et al., 1995).

\section{RESULTADOS E DISCUSSÃO}

Sete $(70 \%)$ dos isolados testados produziram substâncias com atividade antimicrobiana frente à pelo menos uma ou mais das bactérias indicadoras utilizadas (Quadro 2). Esta atividade foi observada somente quando as bactérias foram crescidas em meio ágar 523 de KADO \& HESKETT (1970), não sendo observada em meio ágar NYA. A atividade antimicrobiana dos isolados testados para o crescimento nos meios líquidos não foi observada em nenhum dos meios utilizados frente às bactérias testadas.

Observou-se que a atividade antimicrobiana apresentada pelos isolados foi maior frente as bactérias indicadoras gram-positivas, exceto para o isolado CAR4 ( $B$. liqueniformis) quando testado em relação ao Agrobacterium tumefaciens Ach5. Na determinação da presença de bacteriófagos não foi observada a formação de placas de lise para nenhuma das quatro diluições testadas. Esta atividade de inibição, entretanto, foi predominante somente frente às bactérias gram-positivas e taxonomicamente diferentes dos isolados. Em vista do método adotado para avaliação da ação antimicrobiana dos isolados endofíticos, a provável natureza dos metabólitos com ação inibitória é bacteriocinogênica, o que necessita ser confirmado por outras etapas experimentais de caracterização.

As bacteriocinas de bactérias gram-positivas são mais abundantes e mais diversas do que as de bactérias gram-negativas, geralmente exibindo toxicidade para bactérias gram-positivas, o que pode ser explicado pela pressão evolutiva no ambiente (RILEY \& WERTZ, 2002). As bacteriocinas mais estudadas até hoje são aquelas produzidas por bactérias do gênero Bacillus, geralmente pertencentes à classe dos lantibióticos e especialmente as de origem animal, extensivamente 
visadas para uso como probióticos e na preservação de alimentos (ABRIOUEL et al., 2011). Analisando os resultados obtidos no presente trabalho, a maior parte dos isolados endofíticos desse gênero exibiram ação antimicrobiana frente a algum dos micro-organismos indicadores, principalmente gram-positivos, evidenciando uma provável produção desses derivados peptídicos. Outro fato que pode previamente corroborar que essas são as substâncias responsáveis por essa atividade biológica é a ausência de lise provocada por bacteriófagos quando o teste de detecção dos mesmos foi empregado para analisar se esses seres seriam os responsáveis pela ação biocida frente as bactérias indicadoras.

\begin{tabular}{|c|c|c|c|c|c|c|}
\hline \multirow[b]{2}{*}{ Isolados Endofíticos } & \multicolumn{6}{|c|}{ Bactérias indicadoras } \\
\hline & 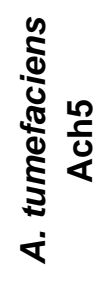 & 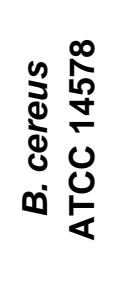 & 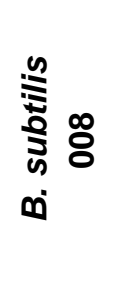 & 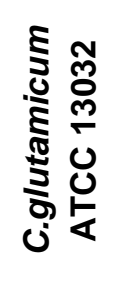 & 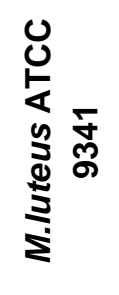 & 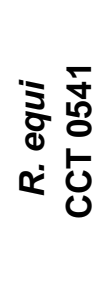 \\
\hline A. pyogenes CAR 1 & - & - & - & - & - & - \\
\hline B. circulans CAR 2 & - & - & - & - & - & + \\
\hline B. coagulans CAR 3 & - & - & - & - & - & + \\
\hline B. licheniformis CAR 4 & + & - & - & - & + & + \\
\hline B. megaterium CAR 5 & - & - & - & + & + & - \\
\hline C. aquaticum CAR 6 & - & + & - & - & - & - \\
\hline C. renale CAR 7 & - & - & + & + & + & \\
\hline P. stutzeri CAR 8 & - & - & - & - & - & - \\
\hline Bacillus sp. CAR 9 & - & - & - & - & - & - \\
\hline Staphylococcus sp. CAR 10 & - & - & - & - & - & + \\
\hline
\end{tabular}

Existem poucos trabalhos na literatura de avaliação e caracterização de bacteriocinas por isolados bacterianos endofíticos. GRAY et al., (2006) caracterizaram a turicina 7 , uma bacteriocina de alto peso molecular de um isolado endofítico de Bacillus thuringiensis que promovia o crescimento vegetal. A bacteriocina possuía um alto peso molecular, ampla atividade antimicrobiana, a qual era mantida após exposição por 15 min a $100^{\circ} \mathrm{C}$ e em condições de $\mathrm{pH}$ variando de 1,0 a 9,25. Em outro estudo, diferentes genótipos de isolados de diversos hospedeiros vegetais do gênero Gluconacetobacter foram testados quanto a atividade antibacteriana contra isolados do mesmo gênero e de outros em meios de cultura sólido, líquido e na planta. Além de ter sido observado um relativo grau de iso-antagonismo em ambas as formas de meios de cultivo e também no vegetal, os autores purificaram e caracterizaram a substância bioativa quanto à estabilidade $e$ verificaram a presença de uma substância proteica de pequeno peso molecular, relativamente resistente a uma ampla faixa de $\mathrm{pH}$, e viável por pelo menos 10 meses a baixa temperatura, salientando inclusive o aproveitamento da produção dessas moléculas semelhantes a bacteriocinas em controle biológico vegetal (MUNOZROJAS et al., 2005). 
ELDEEN (2014) efetuou o isolamento de amostras de bactérias endofíticas de diversas plantas nativas do manguezal malasiano, com uma fração significativa desses isolados demonstrando atividade antimicrobiana frente às cepas indicadoras pelo teste de difusão em ágar e com os extratos brutos proteicos avaliados por teste de microdiluição em placa. No trabalho, as espécies de Bacillus foram as que se sobressaíram quanto a atividade antibacteriana de amplo espectro contra as cepasteste, o que foi visto também no presente estudo. YIN et al., (2011) isolaram e identificaram bactérias endofíticas de árvores de álamo e avaliaram sua atividade frente a diversos fitopatógenos bacterianos e fúngicos, observando uma ampla ação antagonista frente a todos os organismos indicadores de um isolado de Bacillus amyloliquefaciens tanto pelo método de difusão em poço quanto com os extratos livres de células do cultivo em fermentação. Também foi realizada a detecção molecular de genes importantes para a colonização, formação de biofilmes e que estão associados com a ação biocida de endofíticos nesse isolado de Bacillus, o qual se mostrou com profícuo potencial de aplicação para biocontrole de fitopatógenos.

A diferença no espectro inibitório pode variar segundo o meio de cultivo utilizado para a etapa de produção (ROMEIRO, 1989). Dos dois meios de cultivo empregados somente o meio sólido 523 de KADO \& HESKETT (1970) mostrou-se adequado para a produção de bacteriocinas pelos isolados não sendo detectada atividade em meio líquido 523 e em meio sólido ou líquido NYA. VIDAVER et al., (1972) testando a produção de bacteriocinas contra diferentes estirpes fitopatogênicas de Pseudomonas sp. sugeriram que a peptona presente no meio de cultura NYA possa ter inibido a produção de biocinas pelos diferentes isolados testados. Por sua vez, ABO-AMER (2011) em uma pesquisa de otimização das condições de produção de bacteriocinas por um isolado de Lactobacillus acidophillus observou que o extrato de levedura constituiu na melhor fonte de nitrogênio, com a atividade antimicrobiana duas vezes superior quando o extrato foi empregado em comparação com as demais fontes desse elemento. O extrato de levedura foi justamente a fonte de nitrogênio no meio NYA, selecionado no atual trabalho e para o qual não foi verificada posterior ação antimicrobiana, e o meio 523 de KADO \& HESKETT (1970).

A síntese de bacteriocinas ocorreu espontaneamente não sendo necessária a indução por mitomicina $C$ ou a luz ultravioleta, uma vez que a produção de substâncias antagônicas ocorre apenas durante o processo de crescimento do micro-organismo. ECHANDI (1975) e IACOBELLIS et al., (1995) relataram fato semelhante quando determinaram a produção de bacteriocinas por Corynebacterium michiganense e Pseudomonas syringae subsp. savastonoi, respectivamente.

$\mathrm{Na}$ Tabela 1, estão demonstrados os resultados dos testes de resistência ao calor e tripsina dos diferentes isolados endofíticos quando cultivados em meio ágar 523 de KADO \& HESKETT (1970). Os metabólitos antimicrobianos gerados apresentam uma larga variedade de espectro. A maioria dos halos de inibição, independente do produtor e da bactéria indicadora, variaram de 1 a $5 \mathrm{~mm}$ a partir da margem da colônia do isolado. Os compostos antimicrobianos produzidos pelos isolados demonstraram sensibilidade à temperatura e a tripsina. Apenas CAR 4 (Bacillus licheniformis) e CAR 5 (Bacillus megaterium) produziram bacteriocinas com resistência ao tratamento enzimático. 
TABELA 1 - Teste de resistência para os compostos antimicrobianos produzidos em meio ágar 523 por diferentes bactérias endofíticas isoladas de Jacaranda decurrens Cham.

\begin{tabular}{|c|c|c|c|c|}
\hline \multirow[b]{2}{*}{ Bactérias Endofíticas } & \multirow[b]{2}{*}{ Cepas Indicadoras } & \multirow{2}{*}{$\begin{array}{l}\text { Halo }^{*} \\
(\mathrm{~mm})\end{array}$} & \multicolumn{2}{|c|}{ Sensibilidade $^{* *}$} \\
\hline & & & CALOR & TRIPSINA \\
\hline $\begin{array}{l}\text { Bacillus circulans } \\
\text { (CAR 2) }\end{array}$ & R. equi CCT 05410 & 2 & $\mathrm{~S}$ & $\mathrm{~S}$ \\
\hline $\begin{array}{l}\text { Bacillus coagulans } \\
\text { (CAR 3) }\end{array}$ & R. equi CCT 05410 & 5 & S & S \\
\hline \multirow{3}{*}{$\begin{array}{l}\text { Bacillus licheniformis } \\
\text { (CAR 4) }\end{array}$} & M. luteus ATCC 9341 & 3 & $\mathrm{~S}$ & $\mathrm{R}$ \\
\hline & R. equi CCT 05410 & 5 & $S$ & $S$ \\
\hline & A. tumefaciens Ach5 & 2 & $S$ & $S$ \\
\hline \multirow{2}{*}{$\begin{array}{l}\text { Bacillus megaterium } \\
\text { (CAR 5) }\end{array}$} & M. luteus ATCC 9341 & 4 & S & $\mathrm{R}$ \\
\hline & C. glutamicum ATCC 13032 & 2 & $S$ & $S$ \\
\hline \multirow{2}{*}{$\begin{array}{c}\text { Corynebacterium aquaticum } \\
\text { (CAR 6) }\end{array}$} & B. cereus ATCC 14578 & 2 & $\mathrm{~S}$ & $\mathrm{~S}$ \\
\hline & B. subtilis LAB008 & 3 & $S$ & $S$ \\
\hline \multirow{2}{*}{$\begin{array}{c}\text { Corynebacterium renale } \\
\text { (CAR 7) }\end{array}$} & C. glutamicum ATCC 13032 & 3 & $S$ & S \\
\hline & M. luteus ATCC 9341 & 4 & $S$ & $S$ \\
\hline $\begin{array}{c}\text { Staphylococcus sp. } \\
\text { (CAR 10) }\end{array}$ & R. equi CCT 05410 & 5 & S & $S$ \\
\hline
\end{tabular}

Classicamente, as bacteriocinas têm sido amplamente divididas em três grandes classes, principalmente em função do peso molecular: os lantibióticos $\quad<5$ $\mathrm{kDa}$ ) com lantionina; pequenos peptídeos, estáveis ao calor e não possuem lantionina ou seus derivados; e peptídeos de maior peso molecular, sensíveis ao calor e ao tratamento enzimático (PEREZ et al., 2014). Considerando essa categorização, as moléculas geradas por CAR 2, CAR 3, CAR 4, CAR 5, CAR 6, CAR 7 e CAR 10 provavelmente seriam aquelas que se enquadrariam na terceira categoria, pois a atividade antagonista para essas amostras desaparece após serem submetidos a condições de maior temperatura e tratamento enzimático. Por outro lado, pode se sugerir que os isolados CAR4 e CAR 5 produziram bacteriocinas de diferentes naturezas de acordo com essa classificação, uma vez que apresentaram também produção da substância antimicrobiana frente a cepa indicadora $M$. luteus com provável peso molecular baixo, ou seja, sensíveis ao calor e resistentes à enzima tripsina. IACOBELLIS et al., (1995) constataram ser possível que diferentes bacteriocinas possam ser produzidas pela mesma cepa bacteriana, fato que pode ter ocorrido com os isolados CAR 4, CAR 5, CAR 6 e CAR 7.

$O$ interesse na aplicação terapêutica de bacteriocinas e moléculas semelhantes a bacteriocinas geradas por bactérias do gênero Bacillus tem aumentado nos últimos anos, principalmente porque esses compostos possuem um amplo espectro de atividade e especificidade quanto à ação antimicrobiana frente à vários patógenos de interesse em saúde humana e para controle biológico. Dentre os principais metabólitos bioativos produzidos por micro-organismos endofíticos estão esses peptídeos de origem ribossomal (BRADER et al., 2014; SUMI et al., 
2015). Assim, o isolamento e avaliação da atividade antimicrobiana de endofíticos de uma planta medicinal popularmente empregada na medicina tradicional é uma alternativa viável na bioprospecção de organismos produtores dessas moléculas. Esse trabalho representa uma etapa inicial na seleção desses organismos. As perspectivas futuras envolvem a seleção dos isolados que exibiram atividade antimicrobiana e executar experimentos de otimização da produção das bacteriocinas, análise da geração das mesmas em função do tempo, avaliação de outras condições de estabilidade, teste de suscetibilidade frente a fitopatógenos e, claro, a purificação e caracterização proteica desses compostos, para confirmação de sua natureza bacteriocinogênica.

\section{CONCLUSÕES}

De um total de 10 isolados de bactérias endofíticas isoladas de Jacaranda decurrens Cham. (carobinha-do-campo) avaliadas quanto a atividade antimicrobiana por provável produção de bacteriocinas, sete exibiram ação antagonista frente a pelo menos um dos micro-organismos indicadores avaliados. A ausência de lise pelo teste de detecção de bacteriófagos e os padrões de sensibilidade e resistência ao tratamento enzimático sugerem que os metabólitos bioativos sejam de natureza bacteriocinogênica, o que será confirmado por experimentos posteriores a serem realizados. Os resultados obtidos no presente estudo evidenciam o potencial desses micro-organismos endofíticos dessa planta comum conhecida pelas suas propriedades medicinais para geração de novos compostos a serem aplicados como antimicrobianos frente a patógenos microbianos ou no controle biológico vegetal e fomenta a necessidade de exploração do microbioma local dessas plantas quanto a geração de produtos e serviços de interesse para a saúde humana e ambiental.

\section{REFERÊNCIAS}

ABO-AMER, A. E. Optimization of bacteriocin production by Lactobacillus acidophilus AA11, a strain isolated from Egyptian cheese. Annals of Microbiology, v. 61, n. 3, p. 445-452, 2011. Disponível em: <http://dx.doi.org/10.1007/s13213-010-0157-6>. doi: $10.1007 / \mathrm{s} 13213-010-0157-6$

ABRIOUEL, H.; FRANZ, C. M. A. P.; OMAR, N. B.; GALVÉZ, A. Diversityand applications of Bacillus bacteriocins. FEMS Microbiology Reviews, v. 35, n. 1, p. 201-232, 2011. Disponível em: <http://dx.doi.org/10.1111/j.15746976.2010.00244.x>. doi: 10.1111/j.1574-6976.2010.00244.x

BRADER, G.; COMPANT, S.; MITTER, B.; TROGNITZ, F.; SESSITSCH, A. Metabolic potential of endophytic bacteria. Current Opinion in Biotechnology, v. 27, p. 30-37, 2014. Disponível em: <http://dx.doi.org/10.1016/j.copbio.2013.09.012>. doi: 10.1016/j.copbio.2013.09.012

CARRIM, A. J. I.; BARBOSA, E. C.; VIEIRA, J. D. G. Enzymatic activity of endophytic bacterial isolates of Jacaranda decurrens Cham. (Carobinha-do-campo). Brazilian Archives of Biology and Technology, v. 49, n. 3, p. 353-359, 2006. Disponível em: <http://dx.doi.org/10.1590/S1516-89132006000400001>. doi: 10.1590/S151689132006000400001

CAVERA, V. L.; ARTHUR, T. D.; KASHTANOV, D.; CHIKINDAS, M. L. Bacteriocins and their position in the next wave of conventional antibiotics. International Journal 
of Antimicrobial Agents, v. 46, n. 5, p. 494-501, 2015. Disponível em: <http://dx.doi.org/10.1016/j.ijantimicag.2015.07.011>. doi: 10.1016/j.ijantimicag.2015.07.011

CHEBOTAR, V. K.; MALFANOVA, N. V.; SHCHERBAKOV, A. V.; AHTEMOVA, G. A.; BORISOV, A. Y.; LUGTENBERG, B.; TIKHONOVICH, I. A. Endophytic bacteria in microbial preparations that improve plant development. Applied Biochemistry and Microbiology, v. 51, n. 3, p. 271-277, 2015. Disponível em: <http://dx.doi.org/10.1134/S0003683815030059> doi: 10.1134/S0003683815030059

COTTER, P. D.; ROSS, R. P.; HILL, C. Bacteriocins - a viable alternative to antibiotics? Nature Reviews Microbiology, v. 11, n. 2, p. 95-105, 2013. Disponível em: <http://dx.doi.org/10.1038/nrmicro2937> doi:10.1038/nrmicro2937

CRAGG, G. M.; NEWMAN, D. J. Natural products: A continuing source of novel drugs leads. Biochimica et Biophysica Acta (BBA) - General Subjects, v. 1830, n. 6, p. 3670-3695, 2013. $\quad$ Disponível em: <http://dx.doi.org/10.1016/j.bbagen.2013.02.008> doi:10.1016/j.bbagen.2013.02.008

ECHANDI, E.; Bacteriocin production by Corynebacterium michiganense. Phytopathology, v. 66, p. 430-432, 1975. Disponível em: <http://dx.doi.org/ 10.1094/Phyto-66-430>. doi: 10.1094/Phyto-66-430

ELDEEN, I. M. S. Isolation of 12 bacterial endophytes from some mangrove plants and determination of, antimicrobial properties of the isolates and the plant extracts. International Journal of Phytomedicine, v. 6, n. 3, p. 425-432, 2014. Disponível em: <http://dx.doi.org/10.5138/ijpm.v6i3.1435>. doi: 10.5138/ijpm.v6i3.1435

GHOUL, M.; WEST, S. A.; JOHANSEN, H. K.; MOLIN, S.; HARRISON, O. B.; MAIDEN, M. C. J.; JELSBAK, L.; BRUCE, J. B.; GRIFFIN, A. S. Bacteriocin-mediated competition in cystic fibrosis lung infections. Proceedings of the Royal Society $B, v$. 282, n. 1814, p. 1-8, 2015.2 Disponível em: <http://dx.doi.org/10.1098/rspb.2015.0972>. doi:10.1098/rspb.2015.0972

GRAY, E. J.; LEE, K. D.; SOULEIMANOV, A. M.; DI FALCO, M. R.; ZHOU, X.; LY, A.; CHARLES, T. C.; DRISCOLL, B. T.; SMITH, D. L. A novel bacteriocin, thuricin 17, produced by plant growth promoting rhizobacteria strain Bacillus thuringiensis NEB17: isolation and classification. Journal of Applied Microbiology, v. 100, n. 3, p. 545-554, 2006. Disponível em: <http://dx.doi.org/10.1111/j.13652672.2006.02822.x>. doi: 10.1111/j.1365-2672.2006.02822.x

IACOBELLIS, N. S.; CONSTESINI, A. M.; SUCRICO, G. Bacteriocin production by Pseudomonas syringae subsp. savastanoi. Phytopathologia Mediterranea, v. 34, n. 1, p. 15-22, 1995. Disponível em: <http://www.jstor.org/stable/42685961>.

KADO, C. I.; HESKETT, M. G. Selective media for isolation of Agrobacterium, Corynebacterium, Erwinia, Pseudomonas, and Xanthomonas. Phytopathology, v. 60, n. 6, p. 969-976, 1970. Disponível em: <http://dx.doi.org/10.1094/Phyto-60-969>. doi: $10.1094 /$ Phyto-60-969 
MARTINEZ, F. A. C.; BALCIUNAS, E. M.; CONVERTI, A.; COTTER, P. D.; OLIVEIRA, R. P. S. Bacteriocin production by Bifidobacterium spp.: a review. Biotechnology Advances, v. 31, n. 4, p. 482-488, 2013. Disponível em: <http://dx.doi.org/10.1016/j.biotechadv.2013.01.010> doi:10.1016/j.biotechadv.2013.01.010

MESSAOUDI, S.; MANAI, M.; KERGOURLAY, G.; PRÉVOST, H.; CONNIL, N.; CHOBERT, J. M.; DOUSSET, X. Lactobacillus salivarius: Bacteriocin and probiotic activity. Food Microbiology, v. 36, n. 2, p. 296-304, 2013. Disponível em: <http://dx.doi.org/10.1016/j.fm.2013.05.010> doi:10.1016/j.fm.2013.05.010

MUNOZ-ROJAS, J.; FUENTES-RAMÍREZ, L. E.; CABALLERO-MELLADO, J. Antagonism among Gluconacetobacter diazotrophicus strains in culture media and in endophytic association. FEMS Microbial Ecology, v. 54, n. 1, p. 57-66, 2005. Disponível em: <http://dx.doi.org/10.1016/j.femsec.2005.02.011>. doi: 10.1016/j.femsec.2005.02.011

OLIVEIRA, L. G.; PUPO, M. T.; VIEIRA, P. C. Explorando produtos naturais microbianos nas fronteiras da química e biologia. Química Nova, v. 36, n. 10, p. 1577 - $1586,2013 . \quad$ Disponível em: <http://quimicanova.sbq.org.br/imagebank/pdf/Vol36No10_1577_14-NE13632.pdf>

PANDEY, P. K.; YADAV, S. K.; SINGH, A.; SARMA, B. K.; MISHRA, A.; SINGH, H. B. Cross-species alleviation of biotic and abiotic stresses by the endophyte Pseudomonas aeruginosa PW09. Journal of Phytopathology, v. 160, n. 10, p. 532539, 2012. Disponível em: <http://dx.doi.org/10.1111/j.1439-0434.2012.01941.x> DOI: $10.1111 / \mathrm{j} .1439-0434.2012 .01941 . x$

PEREZ, R. H.; ZENDO, T.; SONOMOTO, K. Novel bacteriocins from lactic acid bacteria (LAB): various structures and applications. Microbial Cell Factories, v. 13, n. 1, p. 1-13, 2014. Disponível em: <http://dx.doi.org/10.1186/1475-2859-13-S1-S3>. doi: 10.1186/1475-2859-13-S1-S3

PUGSLEY, A. P.; OUDEGA, B. Methods for studying colicins and their plasmids. In: . HARDY, K. G. (Ed.). Plasmids: a practical approach. Oxford: IRL Press, p.105-262.1987.

RILEY, M. A.; WERTZ, J. E. Bacteriocins: evolution, ecology, and application. Annual Reviews of Microbiology, v. 56, p. 117-137, 2002. Disponível em: <http://dx.doi.org/10.1146/annurev.micro.56.012302.161024>.

doi: 10.1146/annurev.micro.56.012302.161024

ROMEIRO, R. S. Constatação da produção de bacteriocinas por isolamentos de bactérias fitopatogênicas. In:_ ROMEIRO, R. S. (ed.). Métodos em bacteriologia de plantas. Viçosa: Editora UFV, p. 163-172, 1989.

RUTLEDGE, P. J.; CHALLIS, G. L. Discovery of microbial natural products by activation of silent biosynthetic gene clusters. Nature Reviews, v. 13, n. 8, p. 509523, 2015. Disponível em: <http://dx.doi.org/10.1038/nrmicro3496> doi:10.1038/nrmicro3496 
SHARMILA, P. S.; VIDYA, A. K. Characterization and antibacterial activity of bacteriocin producing Bacillus subtilis isolated from raw milk. International Journal on Applied Bioengineering, v. 9, n. 2, p. 1-6, 2015. Disponível em: <http://journalssathyabama.com/archives/upload/vol9-no2-july2015-int-bio-1.pdf>

SUMI, C. D.; YANG, B. W.; YEO, I. C.; HAHM, Y. T. Antimicrobial peptides of the genus Bacillus: a new era for antibiotics. Canadian Journal of Microbiology, v. 61, n. 2, p. 93-103, 2015. <http://dx.doi.org/10.1139/cjm-2014-0613>. doi: 10.1139/cjm2014-0613

UDHAYASHREE, N.; SENBAGAM, D.; SENTHILKUMAR, B.; NITHYA, K.; GURUSAMY, R. Production of bacteriocin and their application in food products. Asian Pacific Journal of Tropical Biomedicine, v. 2, n. 1, p. S406-S410, 2012. Disponível em: <http://dx.doi.org/10.1016/S2221-1691(12)60197-X>. doi:10.1016/S2221-1691(12)60197-X

VIDAVER, A. K., MATHYS, M. L., THOMAS, M. E.; SCHYSTER, M. L. Bacteriocins of the phytopathogens Pseudomonas syringae, $P$. glycinea, and $P$. phaseolicola. Canadian Journal of Microbiology, v. 18, n. 6, p. 705-713, 1972. Disponível em: <http://dx.doi.org/10.1139/w03-107>. doi: 10.1139/w03-107

VIDAVER, A. K. Synthetic and complex media for the rapid detection of fluorescence of phytopathogenic Pseudomonas: effect of the carbon source. Applied Microbiology, v. 15, n. 6, p. 1523-1524, 1967. Disponível em: http://www.ncbi.nlm.nih.gov/pmc/articles/PMC547267/pdf/applmicro00236-0269.pdf>.

WHO, World Health Organization. The world medicines situation 2011. Traditional medicines: global situation, issues and challenges. p. 12, 2011. Disponível em: < http://digicollection.org/hss/documents/s18063en/s18063en.pdf>

YIN, X. T.; XU, L. N.; XU, L.; FAN, S. S.; LIU, Z. Y.; ZHANG, X. Y. Evaluation of the efficacy of endophytic Bacillus amyloliquefaciens against Botryosphaeria dothidea and other phytopathogenic microorganisms. African Journal of Microbiology Research, v. 5, n. 4, p. 340-345, 2011. Disponível em: <http://dx.doi.org/10.5897/AJMR10.679>. doi: 10.5897/AJMR10.679

ZHENG, J.; GÄNZLE, M. G.; LIN, X. B.; RUAN, L.; SUN, M. Diversity and dynamics of bacteriocins from human microbiome. Environmental Microbiology, v. 17, n. 6, p. 2133-2143, 2015. Disponível em: <http://dx.doi.org/10.1111/1462-2920.12662> doi:10.1111/1462-2920.12662 